\title{
EUTANÁSIA: DIREITO À MORTE DIGNA
}

\author{
EUTANASIA: RIGHT TO DEATH WORTHY
}

Matheus Rodrigues Kallas ${ }^{1}$ Rafael de Barros Pustrelo²

ISSUE DOI: $10.21207 / 1983.4225 .370$

\section{RESUMO}

O presente trabalho tem o objetivo de esclarecer o que é a eutanásia, sua origem, suas diferentes modalidades, concentrando-se na eutanásia ativa além de mostrar sua inegável ligação à dignidade humana. Também apontará que carecem motivos para impedir uma pessoa de ser auxiliada a buscar o descanso pacífico e pôr fim à sua dor; que tabus ultrapassados de nada contribuem para o alcance da verdadeira Justiça; que existem questionamentos sobre até onde vai o poder do Estado para tornar a vida uma obrigação, decidindo se a pessoa pode ou não ter um fim tranquilo e digno; que a realidade é cruel: a pessoa é mantida viva, mas não vive.

Palavras-chave: Eutanásia. Vida. Morte. Dignidade.

\footnotetext{
${ }^{1}$ Graduando em Direito pela Faculdade de Direito de Franca, cursando o $5^{\circ}$ ano. Bolsista no Programa de Iniciação Científica da Faculdade de Direito de Franca, apresentando no Congresso de Iniciação Científica. Monitor de Direito Civil IV. Estagiário em escritório de advocacia.

${ }^{2}$ Graduando em Direito pela Faculdade de Direito de Franca, cursando o $5^{\circ}$ ano. Estagiário de Edição da Revista Eletrônica da Faculdade de Direito de Franca. Presidente do Diretório Acadêmico "28 de Março". Presidente do Instituto de Desenvolvimento Sustentável de Franca.
} 


\section{ABSTRACT}

The present work has the objective of clarifying what euthanasia, its origin, its different modalities, concentrating on the active euthanasia in addition to showing its undeniable connection with the human dignity. It will also point out that they lack motives to prevent a person from being helped to seek peaceful rest and put an end to their pain; That outdated taboos of nothing contribute to the attainment of true justice; That there are questions about how far the power of the State is going to make life an obligation, deciding whether or not the person can have a quiet and dignified end; That reality is cruel: the person is kept alive, but does not live.

Keywords: Euthanasia. Life. Death. Dignity.

\section{INTRODUÇÃO}

A eutanásia é um tema controverso em nosso país, tendo tanto quem a defende quanto quem a condena por instintos, sentimentos e crenças pessoais fervorosamente manifestados.

A prática acima referida consiste em dar uma morte piedosa e indolor para pacientes em estado terminal, ou que estão em situações cuja recuperação é impossível e cuja vida é extremamente dolorosa, física e mentalmente.

Na maioria das vezes, tal morte digna é suplicada pelo paciente, que não consegue mais ver o sentido em viver sem poder fazer nada senão sofrer cada dia mais, tornando a espera de sua morte muito pior que essa propriamente dita. Se esse paciente sofre tanto, se deseja pôr um fim em sua vida, por que ele não se mata? A resposta é simples, porém cruel: ele não consegue. Não se trata de falta de coragem, mas sim de incapacidade física para ele mesmo aplicar uma injeção no braço, por exemplo. Além de saber que a morte é a única coisa que o aguarda, ou que passará o resto da vida sem retomar suas atividades, suas paixões, seu ego e orgulho, ele não consegue, sozinho, pôr um fim em sua agonia. Precisaria da ajuda de familiares, amigos e médicos competentes e que compartilhem desse sentimento. A eutanásia seria sua solução.

Porém, nosso ordenamento jurídico não permite a eutanásia, enquadrando quem a executa no tipo previsto pelo artigo $121, \S 1 .^{\circ}$, homi- 
cídio privilegiado, ou no artigo 122, por auxílio ao suicídio, segundo o atual Código Penal.

De fato, é inegável que por legalizar a prática da eutanásia sem nenhuma restrição, muitas vidas sucumbiriam à ganância, maldade e egoísmo daqueles que não prezam o direito à vida. Por outro lado, o que fazer nos casos em que a única solução é a lenta espera da morte, cujo paciente expressa ou tacitamente declara que prefere uma morte rápida, digna e piedosa? Da mesma forma que teve seu direito de viver preservado, não pode ele gozar de um direito de morrer? O Estado tem mesmo autoridade para decidir quem vive e quem morre, interferindo no livre-arbítrio natural ao ser humano? Não é cruel manter a pessoa viva contra sua vontade, fazendo-a esperar por um destino inevitável ou permanecer viva sem viver?

Analisar-se-ão a seguir todas essas indagações.

Expor que o direito à morte também deve ser tutelado é a justificativa do presente trabalho, pois o homem tem o livre-arbítrio para escolher o que fazer com sua vida, não podendo tabus e crenças alheias interferirem nessa escolha, ainda mais quando se trata de algo tão subjetivo quanto à vida e dignidade alheia.

\subsection{CONCEITO E CLASSIFICAÇÕES}

A palavra 'euthanatos' tem origem na Grécia Antiga, e sua etimologia é 'boa morte' ou 'morte sem dor'. O termo "eutanásia” foi criado posteriormente, no século XVII, pelo filósofo Francis Bacon em sua obra "Historia vitaes et mortis" de 1623, para designar o tratamento adequado de doenças incuráveis. É usada quando uma pessoa enferma, sem condições de recuperar-se de sua doença, ou que se encontra em uma situação trágica em que não consegue, por exemplo, mover qualquer membro do corpo, ou perdeu a maioria dos sentidos, recebe uma morte indolor, para findar sua agonia.

Definindo de uma forma mais simples, eutanásia é a morte piedosa dada a uma pessoa em estado terminal, ou que se encontra num es- 
tado de extremo sofrimento causado por doença ou qualquer outro incidente.

É importante distinguir a eutanásia ativa da eutanásia passiva, também conhecida como ortotanásia. Embora os dois tipos sejam meios de abreviar a vida do paciente que sofre de uma enfermidade terminal incurável, lesão ou invalidez irreversível que lhe acarrete graves e insuportáveis sofrimentos, proporcionando-lhe uma morte digna - como apontaram Núñez Paz e Claus Roxin ${ }^{3}$-, a eutanásia ativa caracteriza-se pela adoção de condutas médicas comissivas tendentes a antecipar a morte.

Ortotanásia significa morte correta, ou seja, a morte pelo seu processo natural. Neste caso, o doente já está em processo natural da morte e recebe uma contribuição do médico para que esse estado siga seu curso natural. Somente o médico pode realizar a ortotanásia, e ainda não está obrigado a prolongar a vida do paciente contra a vontade deste e muito menos aprazar sua dor. A ortotanásia é conduta atípica frente ao Código Penal, pois não é causa de morte da pessoa, uma vez que o processo de morte já está instalado.

Desta forma, diante de dores intensas sofridas pelo paciente terminal, consideradas por este como intoleráveis e inúteis, o médico deve agir para amenizá-las, mesmo que a consequência venha a ser, indiretamente, a morte do paciente. ${ }^{4}$

Temos ainda a pratica da distanásia, que se opõe à eutanásia e ortotanásia, consistindo em prolongar, de forma artificial, a vida de um enfermo incurável. Consequentemente, seu sofrimento também é prolongado.

Muitas vezes o desejo de recuperação do doente a todo custo, ao invés de ajudar ou permitir uma morte natural, acaba prolongando sua agonia. Conforme Maria Helena Diniz, "trata-se do prolongamento exagerado da morte de um paciente terminal ou tratamento inútil. Não visa prolongar a vida, mas sim o processo de morte". 5

Fatores geográficos, sociais, políticos e econômicos juntam-se para espalhar pelo nosso continente a morte miserável e precoce de crian-

\footnotetext{
${ }^{3}$ ROXIN, Claus. A apreciação jurídico-penal da eutanásia. Revista Brasileira de Ciências Criminais, São Paulo, v. 08, n. 32, out./dez. 2003.

${ }^{4}$ VIEIRA, Tereza Rodrigues. Bioética e direito. São Paulo: Jurídica Brasileira, 1999. p. 90.

${ }^{5}$ DINIZ, Maria Helena. O estado atual do biodireito. São Paulo: Saraiva, 2001. p. 156.
} 
ças, jovens, adultos e anciãos: a chamada eutanásia social, mais corretamente denominada mistanásia. A fome, condições de moradia precárias, falta de água limpa, desemprego ou condições de trabalho massacrantes, entre outros fatores, contribuem para espalhar a falta de saúde e uma cultura excludente e mortífera.

É precisamente a complexidade das causas dessa situação que gera na sociedade certo sentimento de impotência propício à propagação da mentalidade "salve-se quem puder". Planos de saúde particulares para quem tem condições de pagar e o apelo às medicinas alternativas tradicionais e novas por parte do rico e do pobre, igualmente, são dados sintomáticos de um mal-estar na sociedade diante da ausência de serviços de saúde em muitos lugares e do sucateamento dos serviços públicos e da elitização dos serviços particulares em outros.

Numa sociedade na qual os recursos financeiros consideráveis não conseguem garantir qualidade no atendimento, a grande e mais urgente questão ética que se levanta diante do doente pobre na fase avançada de sua enfermidade não é a eutanásia, nem a distanásia, destinos reservados para doentes que conseguem quebrar as barreiras de exclusão e tornar-se pacientes, mas, sim, a mistanásia, destino reservado para os jogados nos quartos escuros e apertados das favelas ou nos espaços mais arejados, embora não necessariamente menos poluídos, embaixo das pontes das nossas grandes cidades.

Mistanásia por omissão é, sem dúvida, a forma de mistanásia mais espalhada no chamado Terceiro Mundo. Há, porém, formas de mistanásia ativa que merecem breve comentário tanto por causa de sua importância histórica como da tendência de confundi-las com eutanásia.

A política nazista de purificação racial, baseada numa ciência ideologizada, é um bom exemplo da aliança entre a política e as ciências biomédicas a serviço da mistanásia. Pessoas consideradas defeituosas ou indesejáveis foram sistematicamente eliminadas: doentes mentais, homossexuais, ciganos, judeus. Pessoas enquadradas nestas categorias não precisavam ser doentes terminais para serem consideradas candidatas ao extermínio.

Os campos de concentração, com grande quantidade de cobaias humanas à disposição, favoreceram outro tipo de mistanásia ativa. Em nome da ciência, foram realizadas experiências em seres humanos e em nada respeitavam nem a integridade física nem o direito à vida dos parti- 
cipantes. Assim, seres humanos foram transformados em cobaias descartáveis.

A eutanásia ativa, por seu turno, além de uma prática médica voltada para antecipar direta e intencionalmente a morte, também pode se caracterizar como a aceleração da 'morte como resultado indireto das ações médicas que visam do alivio do paciente terminal'. Na eutanásia de duplo efeito ou indireta, portanto, a morte é uma consequência acessória de fazer suportável uma vida próxima a seu fim, ou seja, não é o objetivo imediato da conduta médica, mas o resultado indireto de se ministrar medicamentos que aliviem a dor e o sofrimento do paciente ${ }^{6 .}$

No Brasil, sob o ponto de vista legal, é considerada como atitude criminosa. Em que pese a Resolução n. . . 1.805/2006 do Conselho Federal de Medicina (CFM), não tratar a ortotanásia como ilícito penal, não se pode olvidar que tal procedimento está insculpido no Decreto-Lei n. ${ }^{\circ}$ 2.848 , de 7 de dezembro de 1940, mais precisamente no seu art.121 sendo tratado como homicídio privilegiado, com base no relevante valor moral, conforme aduz o que segue ${ }^{7}$ :

\section{Homicídio simples}

Art 121. Matar alguém:

Pena - reclusão, de seis a vinte anos.

Caso de diminuição de pena

$\S 1 .^{\circ}$ Se o agente comete o crime impelido por motivo de relevante valor social ou moral, ou sob o domínio de violenta emoção, logo em seguida a injusta provocação da vítima, ou juiz pode reduzir a pena de um sexto a um terço.

E a eutanásia ativa não se confunde com o homicídio, porque aquela se realiza para proteger a dignidade do destinatário, buscando reduzir os danos por ele experimentados. Já o homicídio não tem nem uma em outra característica, visto que sua prática não está fundada numa razão

\footnotetext{
${ }^{6}$ SZTAJN apud DIAS, Roberto. $\mathbf{O}$ direito fundamental à morte digna: uma visão constitucional da eutanásia. Belo Horizonte: Fórum, 2012. p. 148-149.

${ }^{7}$ MARINS, André Luis Fernandes. A eutanásia no ordenamento jurídico brasileiro. Disponível em <http://ambito-juridico.com.br/site/index.php/?n_link=revista_artigo s_leitura\&artigo_id=12717\&revista_ca der no=3> Acesso em: 14. mar. 2015.
} 
humanitária e, com ele, não se procura reduzir qualquer dano, mas simplesmente matar ${ }^{8}$.

A eutanásia ativa também se diferencia do suicídio, apesar de nas duas hipóteses ocorrer a opção pela morte. Enquanto a eutanásia é praticada por outra pessoa que não o enfermo e "supõe a aceleração da morte como meio de aliviar os sofrimentos físicos e psíquicos derivados de uma enfermidade terminal"9, no suicídio, além de existir uma coincidência entre o sujeito que pratica o ato e o destinatário da ação, a vida é eliminada por outros motivos ${ }^{10}$.

O tema gera os mais diversos conflitos, sempre colocando em choque a filosofia e a ética em relação à forma que as pessoas se posicionam. Entram em jogo princípios constitucionais, episódios históricos e doutrinas religiosas.

Para esclarecer melhor o assunto, analisar-se-á o conjunto de ciências que formam a Bioética, que fornece uma visão neutra e objetiva do que vem a ser a prática, quais seus benefícios e também suas dificuldades.

No capítulo a seguir, serão expostos os preceitos e metas da Bioética e sua importante função quando se inicia um debate sobre eutanásia.

\section{BIOÉTICA E DIREITOS CONSTITUCIONAIS}

\section{$2.1 \quad$ CONCEITO DE BIOÉTICA}

Bioética é um neologismo construído a partir das palavras gregas bios (vida) e ethos (ética). Van Potter foi o primeiro a utilizar o termo em sua obra "Bioethics: Bridge to the Future" (1971). É o estudo combinado de Ciências da Medicina, Filosofia e Direito, cujo objetivo é in-

\footnotetext{
${ }^{8}$ CALSAMIGLIA. apud DIAS, Roberto. O direito fundamental à morte digna: uma visão constitucional da eutanásia. Belo Horizonte: Fórum, 2012. p. 146.

${ }^{9}$ NÚÑ̃EZ PAZ, Miguel Ángel. Homicídio consentido, eutanásia Y derecho a morir com dignidade: problemática jurídica a la luz del Código Penal de 1995. Madrid: Editorial Tecnos, 1999. p. 60.

${ }^{10}$ CALSAMIGLIA. apud DIAS, Roberto. O direito fundamental à morte digna: uma visão constitucional da eutanásia. Belo Horizonte: Fórum, 2012. p. 159-160.
} 
vestigar questões relacionadas ao delicado funcionamento do início e final da vida humana, animal e ambiental. É a Bioética que investiga temas que atingem a moral da sociedade, e graças a ela são desenvolvidas pesquisas a respeito de clonagem, aborto, formas alternativas de fertilização e, claro, a eutanásia.

Na década de 1970, o termo surgiu com o objetivo de deslocar a discussão acerca dos novos problemas impostos pelo desenvolvimento tecnológico, de um viés mais tecnicista para um caminho mais pautado pelo humanismo, superando a dicotomia entre os fatos explicáveis pela ciência e os valores estudáveis pela ética. A biossegurança, genética em seres humanos, além das velhas controvérsias morais como aborto e eutanásia, requisitava novas abordagens e respostas ousadas da parte de uma ciência transdisciplinar e dinâmica por definição. As diretrizes filosóficas dessa área começaram a consolidar-se após a tragédia do holocausto da Segunda Guerra Mundial, quando o mundo ocidental, chocado com as práticas abusivas de médicos nazistas em nome da ciência, cria um código para limitar os estudos relacionados. Formula-se aí também a ideia que a ciência não é mais importante que o homem. O progresso técnico deve ser controlado para acompanhar a consciência da humanidade sobre os efeitos que eles podem ter no mundo e na sociedade para que as novas descobertas e suas aplicações não fiquem sujeitas a todo tipo de interesse.

Em outubro de 2005, a Conferência Geral da UNESCO adotou a Declaração Universal sobre Bioética e Direitos Humanos, que consolida os princípios fundamentais da bioética e visa definir e promover um quadro ético normativo comum que possa a ser utilizado para a formulação e implementação de legislações nacionais ${ }^{11}$.

No Brasil, a Bioética surgiu tardiamente, em meados da década de 1990, mas é notório o seu crescimento nesse relativo curto espaço de tempo, podendo-se perceber o fato por meio da expansão da criação de programas de pós-graduação lato sensu e strictu sensu em Bioética. A inserção dos conteúdos da Bioética nos currículos de formação dos profissionais das Ciências da Saúde e da Enfermagem possibilitou mudanças na formação ético-moral dos discentes dessa área, de modo a transpor

11 WIKIPÉDIA. Bioética. Disponível em: <http://pt.wikipedia.org/wiki/Bio\%C3\% A9tica> Acesso em: 29. Mar. 2015. 
discussões na academia que se restringiam aos aspectos conceituais que permeiam apenas a deontologia e a ética profissional ${ }^{12}$.

\section{$2.2 \quad$ PRINCÍPIOS DA BIOÉTICA}

Assim como o atual ordenamento jurídico, a Bioética também tem como alicerce princípios, que são a ferramenta de tradução dos valores que devem ser aplicados no cotidiano de quem exerce tal estudo e ciência. É importantíssimo analisar a eutanásia ativa sob o prisma dos princípios bioéticos, pois através deles concluímos a real função e benefício que a morte piedosa pode trazer e que pode evoluir a nossa sociedade, além de assemelharem-se com os princípios do Direito, que serão tratados mais à frente.

\subsubsection{Princípio da Autonomia}

Também conhecido como princípio do respeito às pessoas, o qual está inteiramente ligado ao princípio da dignidade humana. Prega que o indivíduo deve ser reconhecidamente autônomo nas suas decisões. O médico deve respeitar as crenças e os valores morais daquele que está sob seu tratamento, desde que aquela pessoa tenha total conhecimento da situação, e saiba, sem qualquer tipo de influência externa, daquilo que realmente quer, contanto que não prejudique outrem.

Kant em sua doutrina pregava: "A vontade é autônoma quando dá a si mesma sua própria lei (...) Age de tal maneira que o motivo, o princípio que te leve agir, possas tu querer que seja uma lei universal". Os estudos sobre os princípios da autonomia mostram que eles incorporam pelo menos duas convicções éticas: uma se referindo ao tratamento dos indivíduos como agentes autônomos, e outra, que as pessoas com autonomia diminuída devem ser tratadas com maior proteção.

Entendendo-se como pessoa autônoma aquela capaz de decidir sobre sua vontade e objetivos, aquela que é governada por si própria e é

\footnotetext{
${ }^{12}$ MASCARENHAS, Nildo Batista; SANTA ROSA, Darci de Oliveira. Ensino da Bioética na formação do enfermeiro. Disponível em: <http://www.scielo.br/sci elo.php?script=sci_arttext\&pid=S0103-21002010000300 013> Acesso em: 29. Mar. 2015.
} 
capaz de agir intencionalmente ao tomar uma decisão. Essa capacidade de se autogovernar pode ser marcada pela existência de fatores conflitantes internos ou diante de circunstâncias externas. É o exemplo, do menor, do incapaz, do presidiário, do doente mental etc.

\subsubsection{Princípio da Beneficência}

Hipócrates, por volta do ano 430 a.C, em sua obra Epidemia, já aconselhava a classe médica usando esse princípio: "Pratique duas coisas ao lidar com as doenças: auxilie ou não prejudique o paciente". O juramento médico consagra implicitamente esse princípio: "Usarei o poder para ajudar os doentes com o melhor da minha habilidade e julgamento; abster-me-ei de causar danos ou de enganar a qualquer homem com ele".

Defende justamente a ação médica procurando minimizar o mal, agindo sempre em benefício do paciente. Estabelece a obrigação moral de agir em benefício dos outros.

Beneficência quer dizer fazer o bem. De uma maneira prática, isto significa que se tem a obrigação moral de agir para o benefício do outro. Esse conceito, quando é utilizado na área de cuidados com a saúde, que engloba todas as profissões das ciências biomédicas, significa fazer o que é melhor para o paciente, não só do ponto de vista técnicoassistencial, mas também do ponto de vista ético. É usar todos os conhecimentos e habilidades profissionais a serviço do paciente, considerando, na tomada de decisão, a minimização dos riscos e a maximização dos benefícios do procedimento a realizar. O princípio da Beneficência obriga o profissional de saúde a ir além da Não Maleficência (não causar danos intencionalmente) e exige que ele contribua para o bem estar dos pacientes, promovendo ações para prevenir e remover o mal ou dano que, neste caso, é a doença e a incapacidade, e, para fazer o bem, entendido aqui como a saúde física, emocional e mental ${ }^{13}$.

\subsubsection{Princípio da Não Maleficência}

13 LOCH, Jussara de Azambuja. Princípios da bioética. Disponível em: <www.idp.edu.br/component/docman/ doc_download/550>, Acesso em: 29. Mar. 2015. 
De acordo com esse princípio, o profissional de saúde tem o dever de, intencionalmente, não causar mal e/ou danos a seu paciente. Considerado por muitos como o princípio fundamental da tradição hipocrática da ética médica, tem suas raízes em uma máxima que preconiza: "cria o hábito de duas coisas: socorrer (ajudar) ou, ao menos, não causar danos". Esse preceito, mais conhecido em sua versão para o latim (primum non no cere), é utilizado frequentemente como uma exigência moral da profissão médica. Trata-se, portanto, de um mínimo ético, um dever profissional, que, se não cumprido, coloca o profissional de saúde numa situação de má-prática ou prática negligente da medicina ou das demais profissões da área biomédica.

A Não Maleficência tem importância porque, muitas vezes, o risco de causar danos é inseparável de uma ação ou procedimento que está moralmente indicado. No exercício da medicina, esse é um fato muito comum, pois quase toda intervenção diagnóstica ou terapêutica envolve um risco de dano. Por exemplo, uma simples retirada de sangue para realizar um teste diagnóstico tem um risco de causar hemorragia no local puncionado. Do ponto de vista ético, esse dano pode estar justificado se o benefício esperado com o resultado desse exame for maior que o risco de hemorragia. A intenção do procedimento é beneficiar o paciente e não causar-lhe o sangramento. No exemplo anterior, as consequências do dano são pequenas e certamente não há risco de vida. Porém, se o paciente tiver problemas de hemostasia, esse risco ficará aumentado. Quanto maior o risco de causar dano, maior e mais justificado deve ser o objetivo do procedimento para que esse possa ser considerado um ato eticamente correto $^{14}$.

\subsubsection{Princípio da Justiça}

O princípio da justiça está muito próximo do conceito do Princípio da Isonomia. Seria a justiça distributiva do bem e do mal. Em caso de dois pacientes em condições semelhantes, qual o tratamento seria dispensado a um e a outro. Quais os critérios que devem ser usados para o emprego dos meios disponíveis visando o tratamento desses pacientes? Algumas foram propostas por William Frankena:

14 LOCH, Jussara de Azambuja. Princípios da bioética. Disponível em: <www.idp.edu.br/component/docman/doc_download/550>, Acesso em: 29. Mar. 2015. 
1 - A justiça considera, nas pessoas, as virtudes e os méritos;

2 - A justiça trata os seres humanos como iguais, no sentido de distribuir igualmente entre eles, o bem e o mal, exceto, talvez, nos casos de punição;

3 - Trata as pessoas de acordo com suas necessidades, suas capacidades ou tomando em consideração tanto uma quanto outras. ${ }^{15}$

O Relatório Belmonte, sobre ética médica conclui com algumas propostas visando à distribuição igualitária da justiça; "a cada pessoa uma parte igual; a cada pessoa de acordo com a sua necessidade; a cada pessoa de acordo com o seu esforço individual; a cada pessoa de acordo com a sua contribuição à sociedade; a cada pessoa de acordo com o seu mérito".

\subsection{O DIREITO À VIDA}

Não é difícil enxergar que a Bioética e o Direito caminham de mãos dadas, e os princípios daquela são irmãos gêmeos dos princípios deste. Podemos dizer que um dos mais importantes bens tutelados pelo Direito é a vida humana. De que adianta todo um ordenamento jurídico se não há vida humana para dispor dele? Nas palavras de Roberto Dias "a vida é um pressuposto para os outros porque é preciso estar vivo para exercê-los. Sem vida não há direito. Os direitos dependem da vida para existir". ${ }^{16}$

Logo no caput do artigo $5 .^{\circ}$ de nossa Constituição Federal temos tutelada a "inviolabilidade do direito à vida". . No atual Código Civil, os artigos $1 .^{\circ} \mathrm{e} 2 .^{\circ}$ tratam da personalidade da pessoa humana, de que toda pessoa tem capacidade de direitos e deveres na ordem civil, garantindo-a a quem nasce com vida e ainda, colocando a salvo os direitos do nascituro, aquele que ainda foi concebido, cujo nascimento é dado como certo.

Contudo, nada trata explicitamente da morte como um direito. Aborda esse tema - um tabu especialmente para a tradição do pensamento

\footnotetext{
${ }^{15}$ FRANKENA, Willian K. Ética. Rio de Janeiro: Zahar, 1981. p. 61-62.

${ }^{16}$ DIAS, Roberto. $\mathbf{O}$ direito fundamental à morte digna: uma visão constitucional da eutanásia. Belo Horizonte: Fórum, 2012. p. 118.
} 
ocidental - sempre como algo a ser evitado, prevendo, no mais das vezes, sanções aos que praticam atos que levem à morte.

Mas será que a vida, além de um direito e um pressuposto para o exercício de outros direitos, é também uma obrigação, um dever? ${ }^{17}$

A expressão 'inviolabilidade do direito à vida', consagrada constitucionalmente, não indica que a vida é um dever para consigo mesmo e para com os outros, tampouco pode ser entendida como um direito absoluto, indisponível e irrenunciável. Nos termos da Constituição, a 'inviolabilidade' de tal direito significa que ele não tem conteúdo econômico-patrimonial e, mais do que isso, ninguém pode ser privado dele arbitrariamente. Nesse sentido é que ele deve ser entendido como indisponível: ninguém pode dispor da vida de outrem. A inviolabilidade da vida tem a ver com terceiros, cuja ação contra a vida alheia é coibida, mas não se pode ler o texto constitucional de forma a proibir que qualquer pessoa decida sobre a duração de sua vida ${ }^{18}$.

Esse princípio da inviolabilidade da vida está ligado ao princípio ético de que a vida é um bem sagrado, divino. Nosso país outrora teve a religião, política e direito ligados e, mesmo atualmente sendo declarado constitucionalmente um Estado laico, veem-se os resquícios da influência religiosa. Como a maioria da população brasileira segue a doutrina do catolicismo, a vida é encarada como intocável, e mesmo um moribundo sem qualquer chance de recuperação não pode colocar um fim à sua agonia, deve esperar a morte natural se não quiser passar a eternidade ardendo nas chamas infernais.

Seguindo a linha de pensamento de Ronald Dworkin ${ }^{19}$, essa base emocional é mais forte contra a eutanásia, pelo fato de a vida ser caracterizada como um dom divino, um presente de Deus. Contudo, nas modernas democracias pluralistas, a tradição de liberdade indica que não compete ao governo ditar aquilo que seus cidadãos devem pensar sobre valores éticos e espirituais, em especial sobre valores religiosos.

De formar incisiva, Luiz Flávio Gomes, depois de afirmar que ninguém pode ser privado da vida arbitrariamente, assevera que o ser

17 CALSAMIGLIA. apud DIAS, Roberto. O direito fundamental à morte digna: uma visão constitucional da eutanásia. Belo Horizonte: Fórum, 2012. p. 118.

18 SZTAJN. apud DIAS, Roberto. O direito fundamental à morte digna: uma visão constitucional da eutanásia. Belo Horizonte: Fórum, 2012. p. 122.

19 DWORKIN, Ronald. apud DIAS, Roberto. O direito fundamental à morte digna: uma visão constitucional da eutanásia. Belo Horizonte: Fórum, 2012. p. 120. 
humano, dono da vida, deve ser também, dentro de determinadas circunstâncias e segundo certos limites, o dono de sua própria morte. Aliás, já é no suicídio, o que significa, desde logo, uma relativização do 'direito à vida', que equivocadamente tem sido entendido, de modo geral, como algo absolutamente indisponível ${ }^{20}$. Se a vida é indisponível, indisponível também deveria ser a vida tirada no aborto, na guerra e na legítima defesa. Tudo é vida. Se no aborto realizado por uma gravidez resultante de um estupro é permitido, embora exista vida, também na eutanásia a sua aplicação deveria ser permitida em relação àquele que não tem cura ${ }^{21} \mathrm{O}$ abalo emocional que uma mulher sofrerá de ter que carregar no ventre por nove meses um filho gerado pela violência de um estuprador, sofrerá também uma pessoa que recebe a notícia de que sua doença é incurável e lhe restam apenas nove meses de vida, ou alguns anos condicionados à máquinas de um hospital.

\subsection{PRINCÍPIO DA DIGNIDADE HUMANA}

Sem dúvida, trata-se aqui de um dos princípios mais basilares e importantes de todo arcabouço jurídico. Com o fim da Segunda Guerra Mundial, um grande esforço volta-se ao reconhecimento e proteção na dignidade da pessoa humana nas constituições dos Estados, bem como nos tratados internacionais. Sua previsão no ordenamento está logo no artigo $1 .^{\circ}$ do texto da Carta Magna, no inciso III:

A República Federativa do Brasil, formada pela união indissolúvel dos Estados e Municípios e do Distrito Federal, constitui-se como Estado Democrático de Direito e tem como Fundamentos:

I - a soberania;

II - a cidadania;

III - a dignidade da pessoa humana;

IV - os valores sociais do trabalho e da livre iniciativa;

${ }^{20}$ GOMES, Luiz Flávio. Apud DIAS, Roberto. O direito fundamental à morte digna: uma visão constitucional da eutanásia. Belo Horizonte: Fórum, 2012. p. 124-125.

${ }^{21}$ BIZZATO, José Ildeffonso. Eutanásia e a responsabilidade médica. Leme: LED, 2000. p. 124. 


\section{V - o pluralismo político.}

$\mathrm{O}$ art. . $^{\circ}$ da Declaração Universal precisa e explicita a concepção de pessoa da Constituição, recolhendo as inspirações de diversas filosofias e, particularmente, de diversas correntes jusnaturalistas: "Todos os seres humanos nascem livres e iguais em dignidade e em direitos. Dotados de razão e de consciência, devem agir uns para com os outros em espírito de fraternidade" 22

A dignidade humana é quebrada no momento em que o paciente, apesar das várias tentativas de recuperar-se, tem a morte como destino inegável, e ainda assim fica submetido às dores físicas e psicológicas desnecessárias. Seu desgaste na mente e no corpo são a prova de que não resta ali resquício de dignidade humana.

O Estado torna-se contraditório à garantia fundamental da liberdade quando dispõe da vida alheia, impedindo o cidadão de escolher o momento de sua morte, seja na situação de doença sem cura ou um estado vegetativo.

Segundo o filósofo Marcel Conche ${ }^{23}$, sem a liberdade de deixar esta vida, vive-se sem a liberdade de viver porque, não tendo a liberdade de morrer, não se está na vida por escolha, mas encarcerados nela como uma prisão.

Ainda na Carta Magna, conforme o artigo 5. ${ }^{\circ}$, inciso III, "ninguém será submetido à tortura nem a tratamento desumano ou degradante", situação inevitável para manter vivo o enfermo de uma doença cuja cura não foi encontrada, fazendo-o passar por uma experiência dolorosa e desnecessária, uma vez que o próprio não deseja isso.

Para esse enfermo chegar ao ponto de desejar a própria morte, tem-se um sinal claro que sua autonomia e dignidade estão completamente feridas, pois está longe de ser protegida a pessoa que deve sucumbir ao sofrimento extremo que não resultará em nada.

A autora Roxana Borges, esclarece que, "a concepção de dignidade humana que nós temos liga-se à possibilidade de a pessoa conduzir sua vida e realizar sua personalidade conforme sua própria consciência,

${ }^{22}$ MIRANDA, Jorge. Manual de direito constitucional. 2. ed. Coimbra, 1998, p. 89. Disponível em: <http://helenadmab.jusbrasil.com.br/artigos/185079356/eutanasia-e-oprincipio-da-dignidade-da-pessoa-humana>. Acesso em 29 Mar. 2015.

${ }^{23}$ CONCHE, Marcel. Le fondement de lamorale. Paris: PUF, 1993. p. 97. 
desde que não sejam afetados direitos de terceiros" 24 . Esse poder de autonomia também alcança os momentos finais da vida da pessoa.

Ainda, nesse sentido, Ramón Sampedro afirma que "é um grave erro negar a pessoa o direito de dispor da sua vida porque é negar-lhe o direito a corrigir o erro da dor irracional (...) Parece que todos podem dispor da minha consciência. Menos eu!"”. ${ }^{25}$

Apesar da dignidade de pessoa humana ser considerada um atributo indissociável da personalidade, sendo inalienável e indisponível do ser humano, manter uma pessoa em estado terminal, sem qualquer perspectiva de melhora vai totalmente contra à própria dignidade do ser, posto que, a pessoa não possui mais o "mínimo de existência" para se desenvolver e se realizar.

Para Luiz Flávio Gomes,

(...) mesmo de lege data (tendo em vista o ordenamento jurídico vigente hoje), desde que esgotados todos os recursos terapêuticos possíveis e desde que cercada a morte de certas condições razoáveis (anuência do paciente, que está em estado terminal, sendo vítima de grande sofrimento, inviabilidade de vida futura atestada por médicos, etc.), a eutanásia (morte ativa), a morte assistida (suicídio auxiliado por terceiro) e a ortotanásia (cessação do tratamento) não podem ser enfocadas como um fato materialmente típico porque não constitui um ato desvalioso, ou seja, contra a dignidade humana, senão, ao contrário em favor dela. $^{26}$

${ }^{24}$ BORGES, Roxana Cardoso Brasileiro. Eutanásia, ortotanásia e distanásia. Revista Jus Navigandi, Teresina, ano 10, n. 871, 21 nov. 2005. Disponível em: <http://jus.com.br/artigos/7571>. Acesso em: 3 ago. 2015.

${ }^{25}$ SAMPEDRO, Ramón. apud DIAS, Helena. Eutanásia e o princípio da dignidade da pessoa humana.

Disponível em: <http://helenadmab.jusbrasil.com.br/artigos/185079356/eutanasia-e-o-principio-dadignidade-da-pessoa-humana?ref=home> Acesso em: 14. Jun. 2015. ${ }^{26}$ GOMES, Luiz Flávio. Apud DIAS, Roberto. O direito fundamental à morte digna: uma visão constitucional da eutanásia. Belo Horizonte: Fórum, 2012. p. 124-125. 
Condenar alguém a passar seus últimos momentos com vida, sejam esses longos ou curtos, submetendo-o a condições de degradação, humilhação, dores insuportáveis, sofrimento emocional e muitas vezes sozinhos, uma vez que as pessoas próximas se tornam cada vez mais ausentes, viola por completo a dignidade do indivíduo ${ }^{27}$.

\section{EUTANÁSIA NO BRASIL}

No Brasil, não se tem uma legislação vigente que permita a prática explícita da eutanásia, mas também no Código Penal Brasileiro não há tipificação criminal positivada que permita a prática. O que acontece então é uma comparação entre os modos da execução da eutanásia com crimes já vigentes na legislação tendo em vista suprir tais lacunas.

No caso da eutanásia ativa, ou seja, o acordo entre o médico e o paciente ou sua família de aplicar dosagens mais fortes da medicação a fim de que a pessoa não sofra ou sinta mais dor, assumindo como possível consequência a morte, é comparada com o crime de homicídio privilegiado tipificado pelo artigo 121, parágrafo $1 .^{\circ}$ do Código Penal. Privilegiado por ser um ato motivado de valor moral ou social, em que esses valores se justificariam nos interesses pessoais e na mobilidade da sociedade movida de compaixão e piedade. Veja:

Art. 121 - Matar alguém:

Pena - reclusão, de 6 (seis) a 20 (vinte) anos.

Caso de Diminuição de Pena

$\S 1 .^{\circ}$ - Se o agente comete o crime impelido por motivo de relevante valor social ou moral, ou sob o domínio de violenta emoção, logo em seguida a injusta provocação da vítima, o juiz pode reduzir a pena de um sexto a um terço.

A eutanásia passiva, que é a interrupção do tratamento deixando que a doença siga seu curso natural, mesmo com a morte não iminente, é

\footnotetext{
${ }^{27}$ DIAS, Helena. Eutanásia e o princípio da dignidade da pessoa humana. Disponível em: <http://helenadmab.jusbrasil.com.br/artigos/185079356/eutanasia-e-o-principio-dadignidade-da-pessoa-humana?ref=home> Acesso em: 14. Jun. 2015.
} 
comparada a uma omissão de tratamento ou de socorro e, por isso, enquadra-se no artigo 135 do Código Penal:

Art. 135. Deixar de prestar assistência, quando possível fazê-lo sem risco, à criança abandonada ou extraviada, ou a pessoa inválida ou ferida, ao desamparado ou em grave e eminente perigo; ou não pedir, nesses casos socorro da autoridade pública: Pena - detenção, de um a seis meses, ou multa. Parágrafo único. A pena é aumentada da metade, se da omissão resultar lesão corporal de natureza grave, e triplica, se resulta a morte.

Já na ortotanásia, na qual a causa do evento morte já se iniciou e o médico não agiu para salvar a pessoa, a punição é por homicídio culposo, vez que se o crime resulta de inobservância de regra técnica de profissão, arte ou ofício, ou se o agente deixa de prestar imediato socorro à vítima, não procura diminuir as consequências do seu ato, esse responderá pelo artigo 121 , parágrafos $3 .^{\circ}$ e $4 .^{\circ}$ do Código Penal, que tipifica:

Art. $121[\ldots]$

§3. - Se o homicídio é culposo:

Pena - detenção, de 1 (um) a 3 (três) anos.

$\S 4$. $^{\circ}$ - No homicídio culposo, a pena é aumentada de

$1 / 3$ (um terço), se o crime resulta de inobservância de regra técnica de profissão, arte ou ofício, ou se o agente deixa de prestar imediato socorro à vítima, não procura diminuir as consequências do seu ato, ou foge para evitar prisão em flagrante. Sendo doloso o homicídio, a pena é aumentada de 1/3 (um terço) se o crime é praticado contra pessoa menor de 14 (quatorze) ou maior de 60 (sessenta) anos.

Apesar de não existir ainda uma legislação especifica para a eutanásia, muitos foram os projetos criados para uma luta de pós e contras a sua legalização ${ }^{28}$.

\footnotetext{
${ }^{28}$ DAMASCENO, Sabine Pereira da Veiga. A eutanásia e a tutela penal à luz da Constituição Federal. Disponível em: <http://www.conteudojuridico.com.br/artigo.a-
} 
O primeiro pressuposto para se admitir a eutanásia é a disponibilidade do direito à vida - já discutida nesse trabalho -, pois, se esse direito for entendido como indisponível pelo próprio titular, não há como aceitar os comportamentos eutanásticos voluntários.

Contudo, para decidir sobre a própria vida e sobre a própria morte, o paciente deve ser ampla e objetivamente informado sobre os diagnósticos atingidos, os tratamentos recomendados, os riscos envolvidos e os prognósticos esperados. Faz parte da noção de cidadania e dignidade o direito de o paciente ser informado sobre essas questões relativas à sua saúde. Mais do que isso, a informação é um pressuposto para se exercer o direito geral de liberdade no que pertine à condução de sua própria vida e, em uma última análise, de sua própria morte. Trata-se de um requisito imprescindível para o exercício, com responsabilidade, do direito constitucional à autonomia.

$\mathrm{O}$ direito de informação, além de decorrer das disposições dos arts. $1^{\circ}{ }^{\circ}$ incisos II e III, e $5 .^{\circ}$, caput, da Constituição Federal - que tratam, respectivamente, da cidadania, da dignidade e da liberdade -, encontra amparo no art. 5. $^{\circ}$, inciso XIV, da mesma Constituição, que assegura a todos o acesso à informação.

Se este último dispositivo está, realmente, voltado a um direito coletivo à informação, ou seja, de um direito da coletividade à informação, isso não significa que não se refira, também, ao direito de cada pessoa ser informada acerca das questões que lhe digam respeito ou sejam de seu interesse. Mesmo porque, mais adiante, no art. 5..$^{\circ}$ inciso XXXIII, a Constituição impõe aos órgãos públicos o dever de prestar informações a todos que tenham interesse em recebê-las e, nesse caso enquadram-se as informações acerca da saúde do paciente. Se esse dispositivo, com efeito, dirige-se apenas aos órgãos públicos, não se pode esquecer que a assistência à saúde é livre à iniciativa privada (art.199, caput). E as instituições privadas participam do sistema único de saúde, respeitadas as diretrizes impostas por este ( $\$ 1 .^{\circ}$ do mesmo artigo).

O direito à informação, assim, é pressuposto essencial para que o paciente possa decidir acerca do rumo a tomar em relação à sua saúde e, em última análise, à sua vida e à sua morte. Só devidamente informado é que o paciente poderá, livremente, prestar seu consentimento ou manifes- 
tar sua recusa em relação aos procedimentos médicos sugeridos, tendo em vista sua própria dignidade. Adequadamente informado, o paciente poderá exercer seu direito à autonomia ${ }^{29}$.

\subsection{PROJETO DE LEI N. ${ }^{\circ} 125 / 96$}

Em 1996, tramitou no Congresso Nacional o projeto de Lei $\mathrm{n} .^{\circ}$ 125/96 que teve iniciativa do senador amapaense Gilvam Borges, mas nunca entrou em votação.

Nesse projeto a proposta era de que a eutanásia fosse permitida desde que uma junta de cinco médicos atestasse a inutilidade do sofrimento físico ou psíquico do doente, sendo dois especialistas no problema do solicitante. Caso o paciente estivesse impossibilitado de expressar a sua vontade, um familiar ou amigo poderia solicitar à Justiça tal autorização.

Porém o próprio Senador já dizia que o projeto não tinha chances de ser aprovado. E segundo o deputado federal Marcos Rolim, presidente da Comissão de Direitos Humanos da Câmara, "ninguém quer discutir a eutanásia porque isso traz prejuízos eleitorais". Rolim, que é do PT gaúcho, diz que, nos dois anos em que presidiu a comissão, jamais viu o assunto ser abordado. ${ }^{30}$

O projeto de lei foi definido da seguinte forma:

$\mathrm{O}$ art. $2^{\circ}$ permite a eutanásia nos casos de morte cerebral, desde que haja manifestação de vontade do paciente para tanto; seu $\S 1^{\circ}$, dispõe que a manifestação de vontade deve ser expressa e feita como se fosse uma manifestação de última vontade; e $\$ 2^{\circ}$ dispõe sobre a forma de constatação da morte cerebral.

$\mathrm{O}$ art. $3^{\circ}$ aborda a eutanásia nos casos de morte cerebral quando a autorização é dada expressamente pela família. $\mathrm{O} \S 1^{\circ}$ define quem é considerado familiar para efeito da lei. $\mathrm{O} \S 2^{\circ}$ levanta a hipótese do paciente não ter familiares e a autorização; nesse caso, será pedida ao juiz

${ }^{29}$ DIAS, Roberto. O direito fundamental à morte digna: uma visão constitucional da eutanásia. Belo Horizonte: Fórum, 2012. p. 174-175.

${ }^{30}$ DAMASCENO, Sabine Pereira da Veiga. A eutanásia e a tutela penal à luz da Constituição Federal. Disponível em: <http://www.conteudojuridico.com.br/artigo.aeutanasia-e-a-tutela-penal-a-luz-da-constituicao-federal,46732.html> Acesso em: 27. Jul. 2015 . 
pelo médico ou pessoa que mantenha alguma relação de afetividade com o paciente.

$\mathrm{O}$ art. $4^{\circ}$ dispõe que nos casos do art. $3^{\circ}, \S 2^{\circ}$, o juiz deverá ouvir o Ministério Público e mandará publicar citação por edital para que dê ciência aos possíveis familiares. O parágrafo único desse artigo determina que a petição inicial venha obrigatoriamente acompanhada das conclusões da Junta Médica.

$\mathrm{O}$ art. $7^{\circ}$ permite a eutanásia por omissão. Seu $\S 1^{\circ}$ dispõe sobre a avaliação do estado do paciente por uma Junta Médica e exige o consentimento expresso do paciente. $\mathrm{O} \S 2^{\circ}$ aborda a forma pela qual deverá ser dado o consentimento do paciente, que é a mesma prevista no $\S 1^{\circ}$ do art. $2^{\circ} . \mathrm{O}$ art. $3^{\circ}$ permite que a família ou pessoa que mantém laços de afetividade com o paciente requeira autorização judicial para a prática da eutanásia, mas só nos casos de não haver consentimento prévio do paciente e este estar impossibilitado de se manifestar.

$\mathrm{O}$ art. $8^{\circ}$ dispõe que, nos casos do art. $7^{\circ}, \S^{\circ}$, se não houver concordância de todos os familiares, deverá ser instaurado um processo judicial por iniciativa de qualquer familiar.

$\mathrm{O}$ art. $9^{\circ}$ aborda a providência de citação pessoal de todos os familiares do paciente no caso de ocorrer a hipótese do art. $8^{\circ}$. O parágrafo único do art. $9^{\circ}$ dispõe que a petição inicial deve ser instruída das conclusões da Junta Médica.

$\mathrm{O}$ art. 10 e seus parágrafos dispõem sobre a oitiva do Ministério público e a formação da Junta Médica.

$\mathrm{O}$ art. 11 expõe que, após todas as diligências, o juiz deve proferir sentença, decidindo sobre a manutenção da vida ou pela consecução da morte sem dor. $\mathrm{O}$ art. 12 dispõe que da sentença cabe apelação e da decisão pela consecução da morte sem dor o recurso é ex officio para o Tribunal de Justiça ${ }^{31}$.

\subsection{ANTEPROJETO DO CÓDIGO PENAL}

\footnotetext{
${ }^{31}$ DAMASCENO, Sabine Pereira da Veiga. A eutanásia e a tutela penal à luz da Constituição Federal. Disponível em: <http://www.conteudojuridico.com.br/artigo.aeutanasia-e-a-tutela-penal-a-luz-da-constituicao-federal,46732.html> Acesso em: 27. Jul. 2015.
} 
O Anteprojeto do Código Penal altera dispositivos da Parte Especial do Código Penal e também comina ao homicídio a pena de reclusão de 6 a 20 anos laborada pela Comissão de "Alto Nível" nomeada pelo Ministro Íris Rezende. O ilustre Ministro Luiz Vicente Cernicchiaro assinala que o Anteprojeto distingue dois tipos de eutanásia - a ativa e a passiva - já apreciadas no presente estudo.

No projeto da Parte Especial do Código Penal, o $§ 4 .^{\circ}$ do art. 121 aduz:

\begin{abstract}
Art. 121.
$[\ldots]$

$\S 4 .^{\circ}$. Não constitui crime deixar de manter a vida de alguém, por meio artificial, se previamente atestada, por dois médicos, a morte como iminente $\mathrm{e}$ inevitável, e desde que haja consentimento do doente ou, na sua impossibilidade, de ascendente, descendente, cônjuge ou irmão. ${ }^{32}$
\end{abstract}

Tipificada está a eutanásia passiva, também chamada de eutanásia indireta, eutanásia por omissão, ortotanásia ou paraeutanásia. Nesse dispositivo, há expressa exclusão de ilicitude. Não é crime deixar de manter a vida de alguém por meio artificial, se previamente atestada por dois médicos a morte como iminente e inevitável e desde que haja consentimento do paciente ou, em sua impossibilidade, de cônjuge, companheiro, ascendente, descendente ou irmão. Pessoa ligada por estreito vínculo de afeição à vítima não poderá suprir-lhe a anuência.

A eutanásia ativa, apesar de não ser foco de nossas ponderações, está estipulada no $\S 3 .^{\circ}$ do mesmo artigo, dispondo:

Art. 121.

$[\ldots]$

$\S 3 .^{\circ}$ - Se o autor do crime é cônjuge, companheiro, ascendente, descendente, irmão ou pessoa ligada por estreitos laços de afeição à vítima, e agiu por compaixão, a pedido desta, imputável e maior de

\footnotetext{
${ }^{32}$ LIMA NETO, Luiz Inácio de. A legalização da eutanásia no Brasil. Revista Jus Navigandi, Teresina, ano 8, n. 81, 22 set. 2003. Disponível em: <http://jus.com.br/artigos/4217>. Acesso em: 27. Jul. 2015.
} 
dezoito anos, para abreviar-lhe sofrimento físico insuportável, em razão de doença grave e em estado terminal, devidamente diagnosticados:

Pena - reclusão, de dois a cinco anos. ${ }^{33}$

\subsection{PROJETO DE LEI N. ${ }^{\circ} 5.058 / 2005$}

Em oposição à legalização da Eutanásia ou em punições mais brandas para a prática, o Deputado Osmânio Pereira, em 2005, criou um projeto de lei para definir a Eutanásia como um crime hediondo e em sua justificativa dispos que:

Ao garantir os direitos individuais fundamentais e invioláveis a todas as pessoas, sem qualquer distinção e, portanto, sem distinguir, tampouco, o estágio da vida em que se encontrem, a Constituição Federal cita, em primeiro lugar, o direito à vida. Fálo com toda a lógica, posto que, sem esse direito, que é de todos o primeiro, nenhum sentido teriam os demais. ${ }^{34}$

Ainda justificando a criação do projeto e se referindo ao Professor Ives Gandra da Silva Martins, em seu trabalho "Fundamentos do Direito Natural à Vida", repetiu-lhe as palavras dizendo que "o aborto e a eutanásia são violações ao direito natural à vida, principalmente porque exercidos contra insuficientes" ${ }^{\prime 3}$. É indispensável, portanto, que se explicite a natureza hedionda de tais crimes, bem como se vedem legalmente quaisquer ações nesse sentido.

Finalizando, o deputado Osmânio resumiu que:

\footnotetext{
${ }^{33}$ LIMA NETO, Luiz Inácio de. A legalização da eutanásia no Brasil. Revista Jus Navigandi, Teresina, ano 8, n. 81, 22 set. 2003. Disponível em: <http://jus.com.br/artigos/4217>. Acesso em: 27. Jul. 2015.

34 BRASIL. Câmara dos Deputados. PL 5058/2005. Disponível em: <http://www.camara.gov.br/ proposicoesWeb/fichadetramitacao?idProposicao=281681>. Acesso em: 27. Jul. 2015.

${ }^{35}$ Ibidem.
} 
O objeto deste Projeto é a defesa da vida bem como da Constituição e da soberania do nosso País, contra a cultura da morte, que vêm tentando nos impor os países estrangeiros onde isso já impera e contra pessoas e entidades que, conscientemente ou não trabalham à serviço desse propósito assassino. ${ }^{36}$

O projeto foi arquivado no mesmo ano em que foi proposto, pois não obteve apoio. ${ }^{37}$

\section{CONSIDERAÇÕES FINAIS}

"Vida" e "morte" são conceitos que sempre vistos juntos trazem automaticamente nos pensamentos uma sensação maniqueísta, extremos opostos, fugindo da percepção que, na realidade, um está dentro do outro. A morte não é uma situação que se opõe a vida, é apenas a última etapa dessa. Analisando assim, não há sentido em excluí-la no momento da tutela à vida.

O ser humano passa sua existência em função de alcançar seus objetivos, seguir seus sonhos e metas, buscando realizar aquilo que lhe fará bem. Isso é o chamado viver. E esse viver é um dos principais pontos que o Direito visa dar proteção pelo Direito à Vida e à Dignidade Humana presentes na Constituição Federal. Qual a lógica de todo um ordenamento que os garante viver dignamente, se no momento final, não podemos gozar de tal dignidade?

Deixando de tutelar a morte digna, o Estado transforma a vida em uma obrigação, caso a pessoa, por sua situação enferma, não consiga sozinha alcançar o descanso. Carecem interesses do Estado em negar um pedido de morte tranquila vindo de um paciente que não tem recuperação,

36 BRASIL. Câmara dos Deputados. PL 5058/2005. Disponível em: <http://www.camara.gov.br/ proposicoesWeb/fichadetramitacao?idProposicao=281681 >. Acesso em: 27. Jul. 2015.

${ }^{37}$ DAMASCENO, Sabine Pereira da Veiga. A eutanásia e a tutela penal à luz da Constituição Federal. Disponível em: <http://www.conteudojuridico.com.br/artigo,aeutanasia-e-a-tutela-penal-a-luz-da-constituicao-federal,46732.html>. Acesso em: 27 Jul. 2015. 
e prefere ter um fim digno e indolor, do que aguentar dores físicas e psicológicas até o dia em que sua condição de estar vivo ceder.

Quando se argumenta contra a eutanásia ativa, muito é dito que a vida não pertence aos homens, e sim ao Divino que nos concedeu a graça da vida, e somente a Ele, sem exceções, cabe decidir o que fazer com ela. Porém, no momento que é negado o pedido da morte digna, não se está decidindo o destino dessa vida?

A regra divina seria contrariada da mesma forma. Além disso, não são todas as pessoas que seguem tal doutrina religiosa e, sendo um Estado laico, não precisam submeter sua dignidade às convicções que não são as próprias. O ponto principal da prática e da discussão é o momento em que a vida é tirada. Mata-se uma pessoa, portanto, é homicídio.

No atual Código Penal, a eutanásia encaixa-se no tipo do homicídio privilegiado, que se configura quando uma vida é tirada, entre outros, por motivos de relevante, valor social ou moral, tendo a pena diminuída.

É certo que o bem jurídico violado pelo homicídio é o direito à vida, mas, sob outra ótica, analisando os argumentos já expostos em conjunto com os princípios constitucionais e bioéticos, tratando-se da eutanásia ativa, quando requerida pelo paciente sem condições de recuperação ou em estado terminal, nenhum direito ou bem jurídico é violado, e sim é efetivada a dignidade humana no momento final do gozo da vida pelo mesmo.

\section{REFERÊNCIAS BIBLIOGRÁFICAS}

BARATA, Rosinete Souza. Eutanásia: morte digna ou homicídio? Revista Jus Navigandi, Teresina, ano 17, n. 3114, 10 jan. 2012. Disponível em: 〈http://jus.com.br/artigos/20818>. Acesso em: 13. Mar. 2015.

Bioética. Disponível em: 〈http://pt.wikipedia.org/wiki/Bio\%C3\%A9tica〉 Acesso em: 29. Mar. 2015.

BIZZATO, José Ildeffonso. Eutanásia e a responsabilidade médica. Leme: LED, 2000.

BORGES, Roxana Cardoso Brasileiro Borges. Direito de morrer de morrer dignamente: eutanásia, ortotanásia, consentimento informado, testamento vital, análise constitucional e penal e direito compara- 
do. In: SANTOS, Maria Celeste Cordeiro Leite. Biodireito: ciência da vida, os novos desafios. São Paulo: Revista dos Tribunais, 2001.

. Eutanásia, ortotanásia e distanásia. Revista Jus Navigandi, Teresina, ano 10, n. 871, 21 nov. 2005. Disponível em: <http://jus.com.br/ artigos/7571>. Acesso em: 3 ago. 2015.

BRASIL. Câmara dos Deputados. PL 5058/2005. Disponível em: $<$ http://www.camara.gov.br/ proposicoesWeb/fichadetramitacao?idProposicao=281681>. Acesso em: 27. Jul. 2015.

CONCHE, Marcel. Le fondement de lamorale. Paris: PUF, 1993.

DAMASCENO, Sabine Pereira da Veiga. A eutanásia e a tutela penal à luz da Constituição Federal. Disponível em: $<$ http://www.conteudojuridico.com.br/artigo.a-eutanasia-e-a-tutelapenal-a-luz-da-constituicao-federal,46732.html> Acesso em: 27. Jul. 2015.

DIAS, Helena. Eutanásia e o princípio da dignidade da pessoa humana.

Disponível em: <http://helenadmab.jusbrasil.com.br/artigos/185079356/eutanasia-e-oprincipio-da-dignidade-da-pessoa-humana?ref=home> Acesso em: 14. Jun. 2015.

DIAS, Roberto. $\mathbf{O}$ direito fundamental à morte digna: uma visão constitucional da eutanásia. Belo Horizonte: Fórum, 2012.

DINIZ, Maria Helena. O estado atual do biodireito. São Paulo: Saraiva, 2001.

FRANKENA, Willian K. Ética. Rio de Janeiro: Zahar, 1981.

LIMA NETO, Luiz Inácio de. A legalização da eutanásia no Brasil. Revista Jus Navigandi, Teresina, ano 8, n. 81, 22 set. 2003. Disponível em: <http://jus.com.br/artigos/4217>. Acesso em: 27. Jul. 2015.

LOCH, Jussara de Azambuja. Princípios da bioética. Disponível em: <www.idp.edu.br/ component/docman/ doc_download/550>, Acesso em: 29. Mar. 2015.

MAGALHÃES, Brenna Maria Carneiro Costa. Eutanásia: origem, ramificações e outras peculiaridades. In: Âmbito Jurídico, Rio Grande, XVII, n. 121, fev 2014. Disponível em: <http://www.ambitojuridico.com.br/site/?n_link=revista_artig os_leitura\&artigo_i d=1451 9>.Acesso em: 13. Mar. 2015.

MARINS, André Luis Fernandes. A eutanásia no ordenamento jurídico brasileiro.

Disponível

em

$<$ http://ambito- 
juridico.com.br/site/index.php/?n_link=revista_artigos

leitura \&artigo_id=12717\&revista_ca der no=3> Acesso em: 14. mar. 2015.

MARTIN, Leonard M. Eutanásia e distanásia. Disponível em: <http://www.portalmedico.org.br/biblioteca _virtual/bioetica/ParteIIIeutanasia.htm>. Acesso em: 13. Mar. 2015.

MASCARENHAS, Nildo Batista; SANTA ROSA, Darci de Oliveira. Ensino da Bioética na formação do enfermeiro. Disponível em: <http://www.scielo.br/scielo.php? script=sci_arttext\&pid=S010321002010000300 013> Acesso em: 29. Mar. 2015.

MIRANDA, Jorge. Manual de direito constitucional. 2. ed. Coimbra, 1998.

REICHER, Regina Maria. A eutanásia na visão do garantismo penal. Dissertação (Mestrado em Direito) - Pós-Graduação em Direito da Pontifícia Universidade Católica de São Paulo, 2005.

ROXIN, Claus. A apreciação jurídico-penal da eutanásia. Revista Brasileira de Ciências Criminais, São Paulo, v. 08, n. 32, out./dez. 2003.

SÁ, Maria de Fátima. Direito de morrer: eutanásia, suicídio assistido. Belo Horizonte: Del Rey, 2001.

SILVA, Sônia Maria Teixeira da. Eutanásia. Disponível em: <http://www.egov.ufsc.br/ portal/conteudo/ eutan\%C3\%A1sia-3> Acesso em: 14. Mar. 2015.

VIEIRA, Tereza Rodrigues. Bioética e direito. São Paulo: Jurídica Brasileira, 1999. 